\title{
UČINKOVITOST STROJEVA ZA DORADU U POSLOVNOM PROCESU PROIZVODNJE SJEMENA LUCERNE
}

\author{
I. BERAKOVIĆ ${ }^{1}$, G. KRIZMANIĆ ${ }^{1}$, Marijana TUCAK $^{1}$,G. JUKIĆ ${ }^{2}$, \\ M. JOSIPOVIĆ ${ }^{1}$, H. PLAVS̆IĆ ${ }^{1}$, Ilonka IVANIŚIĆ ${ }^{1}$ \\ ${ }^{1}$ Poljoprivredni institut Osijek \\ Agricultural Institute Osijek \\ ${ }^{2}$ Hrvatska agencija za poljoprivredu i hranu - Centar za sjemenarstvo i rasadničarstvo \\ Croatian Agency for Agriculture and Food - Center for Seed and Nursery
}

\section{SAŽETAK}

U procesu proizvodnje kvalitetnog sjemena lucerne potrebno je proizvesti sjeme te ga adekvatno doraditi i skladištiti u skladu sa zakonskim aktima i pravilima struke. Stoga je i ciljovog istraživanja bio utvrditi koji su dijelovi dorade kritične točke dorade te odrediti stupnjeve iskoristivosti svake pojedine faze dorade i tako utvrditi koja faza dorade koliko doprinosi kvaliteti sjemena. U RH najveće količine sjemena proizvode se na području Istarske županije i provedenim istraživanjem je obuhvaćeno pet proizvođača s navedenog agroekološkog područja tijekom tri uzastopne proizvodne godine (2017., 2018. i 2019.). Primarna dorada odrađena je na selektoru i gravitacijskom odjeljivaču, a sekundarna na magnetnom odjeljivaču. Čistoća naturalnog sjemena dopremljenog na doradu kretala se u rasponu od $76 \%$ do $92 \%$. Iskoristivost sjemena u doradi u trogodišnjem istraživanju iznosio je $76,14 \%$. U procesu dorade sjemena lucerne najveća količina otpada bila je na selektoru i kretala se od $16,6 \%$ do $19,8 \%$, dok su otpadi na magnetnom odjeljivaču u svim godinama dorade bili sličnih vrijednosti i iznosili u prosjeku 5,9 \%. Proces dorade potrebno je provoditi sve dok se ne dostigne propisana kvaliteta sjemena. Rezultati istraživanja o učinkovitosti strojeva za doradu sjemena lucerne ukazuju na ovisnost o ulaznim parametrima naturalnog sjemena, a najviše o prisustvu brojnih primjesa na konačnu količinu i kvalitetu sjemena lucerne.

Ključne riječi: Medicago sativa L, dorada, iskoristivost, klijavost

\section{UVOD}

Lucerna (Medicago sativa L.) je višegodišnja biljka koja se smatra jednom od najvažnijih krmnih kultura za proizvodnju kvalitetne i visoko vrijedne stočne hrane. U svijetu je zasijana na oko 30 milijuna hektara lucerne. Od navedenih površina na 
I. Beraković i sur.: Učinkovitost strojeva za doradu u poslovnom

procesu proizvodnje sjemena lucerne

Sjevernu Ameriku otpada 41\%, na Europu 25\%, na Aziju 8\%, a ostatak na Afriku i Oceaniju. Prema Državnom zavodu za statistiku u RH je u 2017. godini bilo zasijano ovom krmnom kulturom 26.057 ha, 2018. godine 24.248 ha, a najviše zasnovanih površina 29.006 ha bilo je u 2019. godini. Prema zasnovanim površinama u RH vidljivo je da se potrebna količina sjemena za tržište RH kreće u rasponu od 250 t do $300 \mathrm{t}$ godišnje. Na temelju izvješća Hrvatske agencije za poljoprivredu i hranu - Centra za sjemenarstvo i rasadničarstvo u RH organizirana je sjemenska proizvodnja lucerne na površini od 282,11 ha (2017.), na 251,0 ha (2018.) i 241,72 ha (2019.). Prema strukturi sortimenata najzastupljenija je 'OS 66' na 109,49 ha,'Osječka 99' na 71,09 ha, 'Os 101 ' na 22,62 ha,'Mirna' na 19,19 ha te 'Plato','Osječka 100' i 'Posavina' na manje od 10 ha.

Lucerna za uzgoj zahtijeva kvalitetno i neutralno zemljište što navode Derscheid i Walstrom (1981), Stjepanović i sur. (1996), Jakšić i sur. (2013), Annicchirico i sur. (2015), te tla bez teških metala (Aydinalp i Mariova, 2009; Stjepanović i sur., 2009; Abasov i sur., 2019). Sjeme namijenjeno daljnjoj proizvodnji mora zadovoljavati odgovarajuće standarde propisane Pravilnikom o stavljanju na tržište sjemena krmnog bilja (NN 129/07, 78/10 31/13, 23/17, 112/18, 47/20) u kojemu su određeni postotak čistoće, klijavostte prisutnost korovskih i drugih biljnih vrsta. Prilikom proizvodnje sjemena dorada predstavlja neizostavan korak, a poznavanje fizikalnih osobina sjemena bitno je u samom procesu prilagođavanja i podešavanja strojeva za doradu.

Naturalno sjeme za doradu složena je mješavina sjemena lucerne, korova te raznih organskih i anorganskih primjesa (Bolanos - Aguilar i sur., 2000). Kako bi se izbjeglo samozagrijavanje sjemena neophodno je odmah nakon žetve pristupiti primarnoj doradi sjemena. O količinama prisutnih nečistoća u naturalnom sjemenu ovisi količina dorađenog sjemena. Selektor i gravitacijski odjeljivač su strojevi na kojima se vrši primarna dorada u proizvodnom procesu. Ovakvo dorađeno sjeme često ne zadovoljava kriterije stavljanja na tržište te se mora pristupiti sekundarnoj doradi. Dorada na magnetnom odjeljivaču predstavlja sekundarnu doradu i tu se ostvaruje visoka kvaliteta čišćenja gdje se iz sjemena izdvajaju korovske vrste.

Cilj istraživanja u ovom radu bio je u procesu dorade sjemena lucerne (1) odrediti iskoristivost nakon pojedine faze dorade, (2) utvrditi odnose između količine naturalnog i dorađenog sjemena te količine otpada nakon primarne i sekundarne dorade, (3) identificirati pokazatelje efikasnosti strojeva u tehnološkom procesu dorade.

\section{MATERIJAL I METODE RADA}

U istraživanju je korišteno sjeme lucerne 'OS 66' koje je proizvedeno na području Istarske županije tijekom tri proizvodne godine (2017., 2018., 2019.) kod pet proizvođača sjemena P1 (Nova Vas), P2 (Grožnjan), P3 (Završje-Grožnjan), P4 (Brtonigla), P5 (Novigrad). Primarna dorada sjemena izvršena je na selektoru Cimbria Heid Delta $102 \mathrm{~s}$ radnim sitima 2,0 Ø (2,0 $\mathrm{mm}$ okruglog otvora), 1,25 \# (1,25 $\mathrm{mm}$ 
I. Beraković i sur.: Učinkovitost strojeva za doradu u poslovnom procesu proizvodnje sjemena lucerne

pravokutnog otvora), $0,7 \#(0,7 \mathrm{~mm}$ pravokutnog otvora) i gravitacijskom odjeljivaču Cimbria Heid GA 31L. Sekundarna dorada izvršena je na magnetskom odjeljivaču Petkus Magnetreiniger K590s upotrebom željeznog praha Hoganas MH300 u pogonu za doradu sjemena Poljoprivrednog instituta Osijek. U laboratoriju prema metodama koje propisuje međunarodna udruga za ispitivanje sjemena [International Seed Testing Association (ISTA, 1999)] analizirani su naturalni uzorci prije procesa dorade te dorađeno sjeme nakon primarne i sekundarne dorade.

Prema meteorološkim podatcima (Tablica 1.) količina oborina u godinama istraživanja bila je viša od višegodišnjeg prosjeka. U 2017. godini ukupne oborine su više za $233 \mathrm{l} / \mathrm{m}^{2}$, u 2018. godini za $112,8 \mathrm{l} / \mathrm{m}^{2}$ dok su u posljednoj godini istraživanja bile više za $353,41 / \mathrm{m}^{2}$ od višegodišnjeg prosjeka. Navedeni podatci pokazuju da su oborine bile u dostatnim količinama i nisu bile ograničavajući faktor proizvodnje sjemena lucerne.

Tablica 1. Ukupne mjesečne oborine u 2017., 2018. i 2019. godini i višegodišnji (1961. - 2019.) prosjek za Istarsku županiju (Pazin)

Table 1 Total monthly precipitation in 2017, 2018 and 2019 and multi-year (1961 - 2019) average for the County of Istria (Pazin)

\begin{tabular}{ccccc}
\hline Mjesec & \multicolumn{4}{c}{$\begin{array}{c}\text { Mjesečna količina oborina } 1 /\left(\mathrm{m}^{2}\right) \\
\left.\text { Monthly precipitation l/( } \mathrm{m}^{2}\right)\end{array}$} \\
Month & 2017. & 2018. & 2019. & $1961-2019$ \\
\hline I & 40,0 & 66,1 & 30,3 & 79,4 \\
II & 190,1 & 124,4 & 151,2 & 80,6 \\
III & 41,5 & 148,8 & 23,4 & 78,4 \\
IV & 90,9 & 57,7 & 135,1 & 85,3 \\
V & 64,3 & 110,1 & 295,1 & 91,0 \\
VI & 44,2 & 138,6 & 26,0 & 93,2 \\
VII & 13,8 & 65,6 & 72,6 & 67,8 \\
VIII & 59,1 & 73,6 & 96,7 & 97,9 \\
IX & 368,3 & 84,5 & 90,5 & 113,6 \\
X & 44,4 & 235,0 & 26,4 & 113,4 \\
XI & 194,1 & 95,4 & 320,3 & 146,0 \\
XII & 226,9 & 57,6 & 230,4 & 98,0 \\
\hline Ukupno / Total & 1377.6 & 1257.4 & 1498 & 1144.6 \\
\hline
\end{tabular}


I. Beraković i sur.: Učinkovitost strojeva za doradu u poslovnom

procesu proizvodnje sjemena lucerne

\section{REZULTATI I RASPRAVA}

Parametri kvalitete naturalnog sjemena dopremljenog u proizvodni proces dorade sjemena lucerne prikazani su u Tablici 2.

Tablica 2. Analiza naturalnog sjemena lucerne tijekom tri proizvodne godine

Table 2 Analysis of natural alfalfa seed during the three production years

\begin{tabular}{|c|c|c|c|c|c|c|c|}
\hline & $\begin{array}{l}\text { Proizvođač } \\
\text { Producer }\end{array}$ & $\begin{array}{c}\text { Masa } \\
\text { Mass } \\
(\mathrm{kg})\end{array}$ & $\begin{array}{c}\text { Čistoća } \\
\text { Purity } \\
(\%)\end{array}$ & $\begin{array}{c}\text { Klijavost } \\
\text { Germination } \\
(\%)\end{array}$ & $\begin{array}{l}\text { Tvrda zrna } \\
\text { Hard grains } \\
\text { (broj) }\end{array}$ & $\begin{array}{l}\text { Cuscuta } \\
\text { (broj) }\end{array}$ & $\begin{array}{l}\text { Rumex } \\
\text { (broj) }\end{array}$ \\
\hline \multirow{5}{*}{ 홍 } & P1 & 1552 & 81 & 65 & 20 & 1 & 0 \\
\hline & P2 & 1500 & 89 & 71 & 18 & 2 & 1 \\
\hline & P3 & 5318 & 85 & 69 & 18 & 4 & 0 \\
\hline & P4 & 9270 & 86 & 71 & 23 & 6 & 0 \\
\hline & P5 & 9840 & 77 & 72 & 14 & 31 & 0 \\
\hline \multirow{5}{*}{$\stackrel{\infty}{\stackrel{\sim}{\sim}}$} & P1 & 2800 & 86 & 69 & 20 & 2 & 1 \\
\hline & $\mathrm{P} 2$ & 1650 & 92 & 66 & 18 & 8 & 0 \\
\hline & P3 & 7600 & 85 & 63 & 14 & 2 & 0 \\
\hline & P4 & 5925 & 84 & 66 & 17 & 5 & 0 \\
\hline & P5 & 6161 & 82 & 67 & 15 & 83 & 0 \\
\hline \multirow{5}{*}{$\stackrel{\circ}{\vec{े}}$} & $\mathrm{P} 1$ & 2835 & 76 & 70 & 16 & 2 & 1 \\
\hline & P2 & 1450 & 86 & 63 & 19 & 4 & 0 \\
\hline & P3 & 3610 & 86 & 64 & 18 & 1 & 0 \\
\hline & P4 & 6585 & 81 & 71 & 14 & 2 & 0 \\
\hline & P5 & 9590 & 85 & 69 & 17 & 11 & 1 \\
\hline & $\begin{array}{l}\text { pno/prosjek } \\
\text { al / average }\end{array}$ & 75686 & 84.06 & 67.73 & 17.4 & 10.93 & 0.26 \\
\hline
\end{tabular}

Ukupna količina naturalnog sjemena dopremljenog na doradu u tri proizvodne godine bila je $75.686 \mathrm{~kg}$. Prosječna čistoća naturalnog sjemena iznosila je 84,06 \%. Najmanja čistoća naturalnog sjemena od 76 \% utvrđena je kod proizvođača P1 u 2019. godini, dok je kod proizvođača P2 u 2018. godini izmjerena najveća vrijednost čistoće od $92 \%$. Đokić i sur. (2019) navode da je uobičajena naturalna čistoća sjemena lucerne od $66 \%$ do $83 \%$. Stjepanović i sur. (2009.) iznose da najmanja čistoća naturalnog sjemena može biti svega 23,2 \% i preciznom doradom možemo izdvojiti sjeme lucerne zadovoljavajuće čistoće. Kvalitetu sjemena uvelike određuje njegova klijavost koja je u trogodišnjem prosjeku iznosila 67,73 \%, kojoj treba pribrojiti i $17,4 \%$ tvrdih zrna. Prisutnost sjemena korova u sjemenu lucerne nikako nije prihvatljiva navode Meshab i Miller (2005.), a u naturalnom sjemenu posebna pažnja pridodaje se prisutnosti sjemena karantenskih korova Cuscute spp. i Rumex spp. U naturalnom sjemenu lucerne trogodišnji prosjek sjemena Cuscuta spp. iznosio je 
I. Beraković i sur.: Učinkovitost strojeva za doradu u poslovnom

procesu proizvodnje sjemena lucerne

10,93 sjemenki na 50 g naturalnog uzorka. Kod proizvođača P5 zabilježena je najviša količina korova Cuscuta spp. u naturalnom uzorku i to u sve tri godine istraživanja, au 2018. godini iznosila je 83 sjemenke Cuscuta spp. u uzorku od 50 g naturalnog sjemena. Kod svih proizvođača u trogodišnjem istraživanju proizvodne površine lucerne su iste te se sukcesivno povećava broj korova na tablama zbog neodgovarajuće tehnologije u borbi sa zaštitom od korova. Prosječna količina Rumexspp. iznosila je 0,26 sjemenki ovog korova na 50 guzorka.

Broj prohoda sjemena na strojevima za doradu i količine otpada nakon primarne $\mathrm{i}$ sekundarne dorade sjemena lucerne prikazani su u Tablici 3.

Nakon dorade naturalnog sjemena na selektoru i gravitacijskom odjeljivaču, što predstavlja primarnu doradu sjemena, prosječna količina otpada iznosila je 17,95 \%. Đokići sur. (2018.) u istraživanju dorade crvene djeteline zabilježili su prosječne otpade od 15,95\%. Najmanja količina otpada nakon primarne dorade iznosila je 9,1\% i zabilježena je kod proizvođača P2 u 2018. godini dok je najveća količina otpada bila kod proizvođača P1 u 2019.godini i iznosila je visokih $27.7 \%$.

Tablica 3. Analiza otpada nakon primarne i sekundarne dorade tijekom tri proizvodne godine Table 3 Analysis of waste after primary and secondary processing during the three production years

\begin{tabular}{|c|c|c|c|c|c|c|}
\hline \multirow{2}{*}{$\begin{array}{l}\text { Godina } \\
\text { Year }\end{array}$} & \multirow{2}{*}{$\begin{array}{c}\text { Proizvođač } \\
\text { Producer }\end{array}$} & \multicolumn{2}{|c|}{$\begin{array}{l}\text { Primarna dorada } \\
\text { Primary finishing }\end{array}$} & \multicolumn{2}{|c|}{$\begin{array}{l}\text { Sekundarna dorada } \\
\text { Secondary finishing }\end{array}$} & \multirow{2}{*}{$\begin{array}{c}\text { Ukupno } \\
\text { Otpad } \\
\text { Total } \\
\text { waste } \\
\%\end{array}$} \\
\hline & & $\begin{array}{c}\text { Broj } \\
\text { prohoda } \\
\text { Passes }\end{array}$ & $\begin{array}{c}\text { Otpad } \\
\text { Waste } \\
\%\end{array}$ & $\begin{array}{c}\text { Broj } \\
\text { prohoda } \\
\text { Passes }\end{array}$ & $\begin{array}{c}\text { Otpad } \\
\text { Waste } \\
\%\end{array}$ & \\
\hline \multirow{5}{*}{ 홍 } & $\mathrm{P} 1$ & 1 & 18.8 & 1 & 3.9 & 22.7 \\
\hline & $\mathrm{P} 2$ & 2 & 10.3 & 2 & 5.7 & 16 \\
\hline & P3 & 1 & 17.6 & 2 & 5.5 & 23.1 \\
\hline & $\mathrm{P} 4$ & 1 & 16.3 & 3 & 6.4 & 22.7 \\
\hline & P5 & 1 & 24 & 6 & 8.4 & 32.4 \\
\hline \multirow{5}{*}{$\stackrel{\infty}{\stackrel{\infty}{i}}$} & $\mathrm{P} 1$ & 2 & 15.7 & 1 & 2.9 & 18.6 \\
\hline & $\mathrm{P} 2$ & 2 & 9.1 & 2 & 3.9 & 13 \\
\hline & P3 & 1 & 19.7 & 2 & 4.1 & 23.8 \\
\hline & $\mathrm{P} 4$ & 1 & 16.4 & 1 & 8.8 & 25.2 \\
\hline & P5 & 1 & 22.2 & 5 & 9.5 & 31.7 \\
\hline \multirow{5}{*}{$\stackrel{\curvearrowright}{\stackrel{\sim}{~}}$} & $\mathrm{P} 1$ & 2 & 27.7 & 3 & 7.6 & 35.3 \\
\hline & $\mathrm{P} 2$ & 1 & 15.9 & 2 & 6.2 & 22.1 \\
\hline & P3 & 1 & 18.7 & 1 & 2.6 & 21.3 \\
\hline & $\mathrm{P} 4$ & 1 & 26.3 & 2 & 4.5 & 30.8 \\
\hline & P5 & 1 & 10.5 & 3 & 8.6 & 19.1 \\
\hline \multicolumn{2}{|c|}{ Prosjek / Mean } & 1.27 & 17.95 & 2.4 & 5.91 & 23,86 \\
\hline
\end{tabular}

Nakon primarne dorade sjemena lucerne na selektoru i gravitacijskom odjeljivaču sjeme je najčešće potrebno doraditi na magnetnom odjeljivaču i izdvojiti sjeme 
I. Beraković i sur.: Učinkovitost strojeva za doradu u poslovnom procesu proizvodnje sjemena lucerne

korovskih vrsta što predstavlja sekundarnu doradu. Količina otpada nakon sekundarne dorade mnogo je manja u odnosu na primarnu doradu i u trogodišnjem istraživanju u prosjeku je iznosila 5,91 \%. Kod proizvođača P5 zabilježena je najveća količina otpada nakon sekundarne dorade sjemena lucerne i bila je znatno veća od trogodišnjeg prosjeka, a kretala se u rasponu od 8,4 \% (2017.) do 9,5 \% (2018.). Količine otpada nakon dorade potvrđuje Čajić (1994.) te Stjepanović i sur. (2009.). Čajić i Stjepanović (1995.) navode da su u istraživanju zabilježili 14,69 \% otpada na selektoru i 5,71 \% otpada na magnetnom odjeljivaču. Da se ostvari učinkovito odstranjivanje korova iz sjemena lucerne nekada je potrebno više puta naturalno sjeme doraditi preko magnetnog odjeljivača. Kako bi se postigla propisana kvaliteta i čistoća sjemena u 2017. godini masa sjemena proizvođača P5 dorađivana je šest puta na magnetnom odjeljivaču. Slične podatke iznosi Đokić i sur. (2017.), a Uhlarik i sur. (2018.) navodi da su otpadi nakon sekundarne dorade sjemena lucerne iznosili između 7,8 i $9,8 \%$.

Ukupna količina otpada u procesu dorade u trogodišnjem prosjeku iznosila je 23,86 \%. Najmanje ukupnog otpada $13 \%$ nakon dorade imao je proizvođač P2 u 2018. godini, dok je najveća količina otpada nakon dorade bila kod proizvođača P1 u 2019. godini i iznosila je $35.3 \%$.

Kvaliteta sjemena lucerne na kraju doradbenog procesa proizvodnje sjemena i dorade na strojevima za doradu prikazana je u Tablici 4 .

Tablica. 4 Kvaliteta sjemena lucerne nakon dorade tijekom tri proizvodne godine

Table 4 Alfalfa seed quality after processing during three production years

\begin{tabular}{|c|c|c|c|c|c|c|}
\hline $\begin{array}{c}\text { Godina } \\
\text { Year }\end{array}$ & $\begin{array}{c}\text { Proizvođač } \\
\text { Producer }\end{array}$ & $\begin{array}{l}\text { Radman } \\
\text { Radman } \\
\quad(\%)\end{array}$ & $\begin{array}{c}\text { Čistoća } \\
\text { Purity } \\
(\%)\end{array}$ & $\begin{array}{l}\text { EK } \\
(\%)\end{array}$ & $\begin{array}{l}\text { SK } \\
(\%)\end{array}$ & $\begin{array}{l}\text { Tvrda zrna } \\
\text { Hard grain } \\
\quad \text { (broj) }\end{array}$ \\
\hline \multirow{5}{*}{$\frac{\bar{\sigma}}{\mathrm{N}}$} & P1 & 77.3 & 98.2 & 65 & 79 & 9 \\
\hline & $\mathrm{P} 2$ & 84 & 99.5 & 75 & 83 & 7 \\
\hline & P3 & 76.9 & 96.9 & 69 & 82 & 10 \\
\hline & $\mathrm{P} 4$ & 77.2 & 98.3 & 76 & 86 & 6 \\
\hline & P5 & 67.6 & 99.1 & 66 & 85 & 7 \\
\hline \multirow{5}{*}{$\stackrel{\infty}{\stackrel{2}{\circ}}$} & $\mathrm{P} 1$ & 81.4 & 99.5 & 86 & 86 & 4 \\
\hline & $\mathrm{P} 2$ & 87 & 99.8 & 88 & 89 & 4 \\
\hline & P3 & 76.2 & 99.3 & 86 & 87 & 3 \\
\hline & P4 & 74.8 & 99.8 & 82 & 83 & 3 \\
\hline & P5 & 68.3 & 96.6 & 78 & 81 & 4 \\
\hline \multirow{5}{*}{ 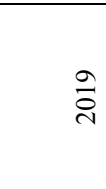 } & P1 & 64.7 & 96.6 & 85 & 86 & 4 \\
\hline & $\mathrm{P} 2$ & 77.9 & 98.7 & 83 & 85 & 4 \\
\hline & P3 & 78.7 & 99.1 & 78 & 82 & 5 \\
\hline & P4 & 69.2 & 98.8 & 76 & 81 & 4 \\
\hline & P5 & 80.9 & 99.1 & 77 & 82 & 4 \\
\hline \multicolumn{2}{|c|}{ Ukupno / Total } & 76.14 & 98.6 & 78 & 83.8 & 5.2 \\
\hline
\end{tabular}


I. Beraković i sur.: Učinkovitost strojeva za doradu u poslovnom

procesu proizvodnje sjemena lucerne

Iskoristivost sjemena u doradi tijekom tri godine istraživanja u prosjeku je iznosila $76,14 \%$, a kretala se od 64,7 \% - 87 \%. Đokić i sur. (2019.) u svom istraživanju navode da je iskoristivost sjemena lucerne u rasponu od 58,25 \% do 72,2 \%. Prosječna čistoća sjemena lucerne nakon dorade iznosila je 98,6 \%. Slične rezultate o čistoći sjemena lucerne nakon dorade iznose Đukanović i sur. (2009.) i Đokići sur. (2016.). Fiziološka vrijednost sjemena izražena je s energijom klijanja i standardnom klijavosti sjemena, gdje je energija klijanja u prosjeku iznosila $78 \%$, a standardna klijavost $83,8 \%$. Ovim vrijednostima treba pribrojati i u prosjeku 5,2 \% tvrdih zrna, koja su se kretala u rasponu od 3 do 10 tvrdih sjemenki lucerne.

\section{ZAKLJUČAK}

$\mathrm{Na}$ temelju provedenih istraživanja vidljivo je da u naturalnom sjemenu lucerne ima visoki postotak primjesa koje je potrebno izdvojiti u poslovnom procesu proizvodnje sjemena. Proces dorade obuhvaća primarnu i sekundarnu doradu koja pokazuje na učinkovitost strojeva za doradu sjemena lucerne. Svaka faza dorade različito doprinosi kvaliteti sjemena lucerne. U primarnoj doradi na selektoru i gravitacijskom odjeljivaču izdvajamo najveće količine primjesa, dok u sekundarnoj fazi dorade na magnetnom odjeljivaču izdvajamo korovske vrste iz sjemenske mase.

Prosječna količina otpada u trogodišnjem istraživanju iznosila je 23,86 \%, a kretala se od $13 \%$ do $35,3 \%$ iz čega se zaključuje da velika razlika kod otpada nastaje zbog neujednačenosti proizvedenih naturalnih količina sjemena lucerne a koje ovise o proizvodnim površinama i njihovoj zakorovljenosti. Prosječna trogodišnja vrijednost otpada svih proizvođača nakon primarne dorade iznosila je 17,95 \%, a nakon sekundarne $5,91 \%$.

Da bi se ostvarila propisana kvaliteta sjemena i izdvojili karantenski korovi ponekada je potrebno ponoviti više puta proces na magnetnom odjeljivaču. Iskoristivost dorađenog sjemena $u$ trogodišnjem istraživanju iznosio je $76,14 \%$, s ostvarenom prosječnom čistoćom sjemena lucerne od 98,6 \%. Energija klijanja iznosila je $78 \%$, a standardna klijavost $83,8 \%$, kojoj se pribraja i količina tvrdih zrna koje su u trogodišnjem istraživanju u prosjeku iznosile 5,2 \%. Vidljivo je da se kvalitetnom doradom u pogonima za doradu sjemena mogu ostvariti propisani visoki kriteriji $u$ pogledu kvalitete sjemena.

Rezultati istraživanja učinkovitosti strojeva za doradu sjemena lucerne ukazuju na ovisnost količine i kvalitete sjemena lucerne o ulaznim parametrima naturalnog sjemena, a najviše o prisutnosti brojnih primjesa za koje je poželjno da ih je što manje u naturalnom sjemenu.

Iz rezultata istraživanja može se zaključiti da se u proizvodnji sjemena lucerne s velikom pažnjom mora voditi briga o zakorovljenosti proizvodnih površina. U procesu dorade sjemena lucerne mora se težiti preciznosti i učinkovitosti strojeva za doradu sjemena. 
I. Beraković i sur.: Učinkovitost strojeva za doradu u poslovnom

procesu proizvodnje sjemena lucerne

\title{
EFFICIENCY OF FINISHING MACHINES IN THE BUSINESS PROCESS OF ALFALFA SEED PRODUCTION
}

\author{
SUMMARY
}

Alfalfa is a perennial plant that is considered the most important foddercrop for the production of quality fodder. Ensuring sufficient quantities of quality seeds is the first prerequisite in the process of producing quality foddermass of alfalfa, and high-value seeds are obtained by processing and properstorage of processed seeds. The aim of the research was to determine the yields of processing after each phase of processing in the process of alfalfa seed processing and thus determine contribution of each phase of processing to the quality of seeds.

In the Republic of Croatia, the largest quantities of alfalfa seeds are produced in the Istrian County, and the conducted research covered five producers from the mentioned agro-ecological are a during three consecutive production years $(2017,2018$ and 2019). The primary processing was done on a selector and a gravity separator, and the secondary on a magnetic separator. The purity of natural seeds delivered for processing ranged from $76 \%$ to $92 \%$.

The processing yield in the three-year survey was $76.14 \%$. In processing alfalfa seeds, the largest amount of waste was on the selector and ranged from $16.6 \%$ to $19.8 \%$, while the waste on the magnetic separator in all years of processing was of similar value and averaged 5.9\%.

Seed processing must be carried out until the prescribed seed quality is reached. The results of research on the efficiency of alfalfa seed processing machines indicate the dependence on the input parameters of natural seeds, and most of all on the presence of numerous impurities on the final quantity and quality of alfalfa seeds.

Key words: Medicago sativa L, finishing, seed utilization, germination

\section{LITERATURA - REFERENCES}

1. Abasov M. S., Abasov S. M., Husainov H. A., ShishkhaevI. Y., Bekbulatov R. K. (2019.): Effect of Seeding Methods on Productivity of Alfalfa Crops, KnE Life Sciences, 4(14), 842-850.

2. Annicchiarico, P., Barrett, B., Brummer, E.C., Julier, B., Marshall, A.H. (2015.) Achievements and challenges in improving temperate perennial for agelegumes. Critical Reviewsin Plant Sciences, 34,327-380.

3. Aydinalp C. and Marinova S., (2009.): The effects of heavy metals on seed germination and plant growth on alfalfa plant (Medicago sativa L.). Bulg. J. Agric. Sci., 15, 347-350. 


\section{Beraković i sur.: Učinkovitost strojeva za doradu u poslovnom procesu proizvodnje sjemena lucerne}

4. Bolanos-Aguilar E. D., Huyghe C., Julier B., Ecalle C. (2000.): Genetic variation for seed yield and its components in alfalfa (Medicago sativa L.) populations, Agronomie 20, 333345.

5. Čajić V. (1994.): Utjecaj korova i drugih primjesa u sjemenu lucerne na gubitke i kvalitet sjemena u procesu dorade, Magistarski rad, Poljoprivredni fakultet Osijek.

6. Čajić V. i Stjepanović M. (1995.): Utjecaj korova na gubitke sjemena lucerne tijekom čišćenja, Sjemenarstvo, 12 (2-3), 123-134.

7. Derscheid L. A. and Walstrom R. J., (1981.): Alfalfa Seed Production,SDSU Extension Circulars, 433.

8. Đokić D., Stanisavljević R., Terzić D., Milenković J., Lugić Z., Barać S., Vuković A. (2016.): Uticaj korovskih vrsta na efikasnost dorade semena crvene deteline (Trifoliumpratense L.), Naučno-stručni skup Aktuelni problemi mehanizacije poljoprivrede, Zbornik radova, str. 2937.

9. Đokić D., Stanisavljević R., Terzić D., Milenković J., Lugić Z., Koprivica R., Barać S. (2017.): The impact of the natural seed purity on the final quantity of seeds of red clover (Trifolium pratense L.) after processing, VIII International Scientific Ag. Symposium, Oct. 05.08.2017., Jahorina, Bosnia and Herzegovina, Book of proceedings, 513-518.

10. Đokić D., Stanisavljević R., Terzić D., Milenković J., Lugić Z., Radović J., Knežević J. (2018.): Određivanje relevantnih parametara pri doradi semena crvene deteline (Trifoliumpratense L.), Selekcija i semenarstvo, vol. 24, br. 1, str. 57-64.

11. Đokić D., Stanisavljević R., Terzić D., Milenković J., Kozlov V., Koprivica R., Vuković A. (2019.): Parametri efikasnosti mašina za doradu semena crvene deteline i lucerke, Poljoprivredna tehnika, vol. 44, br. 1, str. 10-18.

12. Đukanović L., Filipović Đ., Glumac I., Dević A. (2009.): Efekat različitih faza dorade na čistoću semena lucerke, Časopis za procesnu tehniku i energetiku u poljoprivredi / PTEP, vol. 13, br. 3, str. 268-270.

13. ISTA (1999.): International rules for seed testing 1999. Seed Sciand Technol, 27 Supplement, 1333.

14. Jakšić S. P., Vučković S. M., Vasiljević S., Grahovac N., Popović V., Šunjka D. B., Dozet G. K. (2013.): Akumulacija teških metala u Medicago sativa L. i Trifolium pratense L. na kontaminiranom fluvisolu, Hemijska industrija, vol. 67, br. 1, str. 95-101.

15. Meshab O. A. and Miller S. D. (2005.): Canada Thistle (Cirsium arvense) Controlin Established Alfalfa (Medicago sativa) Grown for Seed Production, Weed Technology 19(4), 10251029.

16. Stjepanović M., Popović S., Grljušić S., Bukvić, G. (1996.): Proizvodnja sjemena lucerne i crvene djeteline-značajan čimbenik proizvodnje voluminozne krme // Zbornik sažetaka / Kolak, Ivan (ur.), Zagreb, Hrvatsko agronomsko društvo, Sekcija oplemenjivanje bilja i sjem, 1996. str. $77-78$.

17. Stjepanović M., Zimmer R., Tucak M., Bukvić G., Popović S. i Štafa Z. (2009.): Lucerna, Sveučilište Josipa Jurja Strossmayera u Osijeku, Poljoprivredni fakultet Osijek, Poljoprivredni institut Osijek.

18. Uhlarik A., Popov S., Karagić Đ., Ponjičan A., Turan J. (2018.): Prečišćavanje semena lucerke na magnetnom prečistaču, Journal on Processing and Energy in Agriculture, vol. 22, br. 4, str. 192-195.

19. ***Državnom zavodu za statistiku (https://www.dzs.hr 15.02.2021.)

20. ***HAPIH-Centar za sjemenarstvo i rasadničarstvo (https://www.hapih.hr 15.02.2021.)

21. ***Pravilnik o stavljanju na tržište sjemena krmnog bilja (NN 129/07, 78/10 31/13, 23/17, 112/18, 47/20) (15.02.2021.) 
I. Beraković i sur.: Učinkovitost strojeva za doradu u poslovnom procesu proizvodnje sjemena lucerne

Adrese autora - Authors adresses:

Dr. sc. Ivica Beraković

e-mail: ivica.berakovic@poljinos.hr

dr. sc. Goran Krizmanić

dr. sc. Marijana Tucak

dr. sc. Marko Josipović

dr. sc. Hrvoje Plavšić

Ilonka Ivanišić, dipl. ing.

Poljoprivredni institut Osijek,

Južno predgrađe 17, Osijek, Hrvatska

dr. sc. Goran Jukić

Hrvatska agencija za poljoprivredu i hranu

Centar za sjemenarstvo i rasadničarstvo,

Usorska 19, Brijest, Hrvatska
Primljeno - Received:

24.02.2021 